\title{
BIS
}

Working paper No. 22

\section{CONTAGIOUS SPECULATIVE ATTACKS}

\author{
by
}

Stefan Gerlach and Frank Smets

September 1994

BANK FOR INTERNATIONAL SETTLEMENTS

Monetary and Economic Department

BASLE 


\title{
CONTAGIOUS SPECULATIVE ATTACKS ${ }^{*}$
}

\author{
by
}

\author{
Stefan Gerlach and Frank Smets
}

September 1994

\begin{abstract}
During the European exchange market turmoil in 1992-93 it was evident that speculative attacks tended to spread across currencies. Using a twocountry version of the model developed by Flood and Garber (1984) we show how a speculative attack against one currency may accelerate the "warranted" collapse of a second parity. More importantly, even if the parity of the second currency is viable in the absence of a collapse of the first one, it might be subjected to a speculative attack if the reserves available to defend the parity are "small".
\end{abstract}

* An earlier version of the paper was entitled "Contagion effects of speculative attacks against fixed exchange rate regimes". The paper was prepared for the conference on "Small Countries and the EMU" held at the University of Joensuu, Finland, on 24th June 1993. We thank our discussant, Alpo Willman, two anonymous referees and seminar participants at the BIS, IUHEI in Geneva and INSEAD in Fontainebleau for helpful comments. 


\section{Contents}

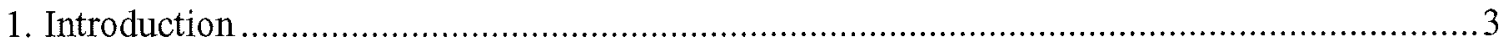

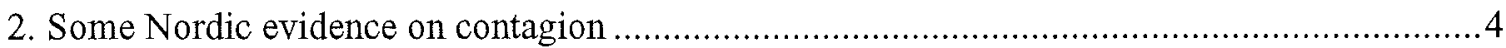

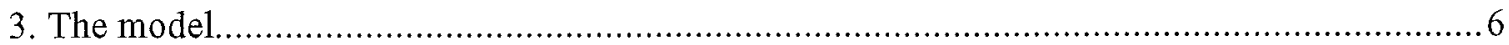

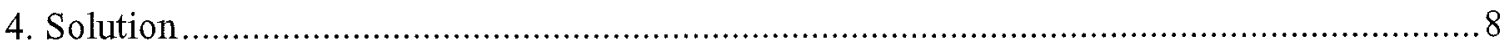

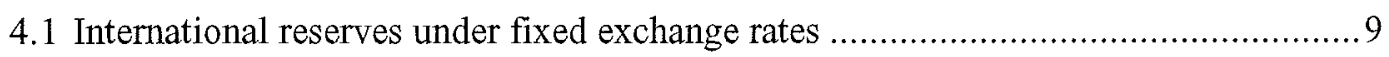

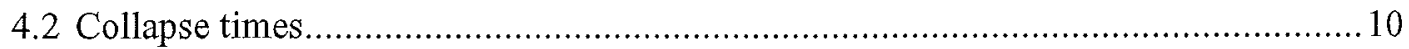

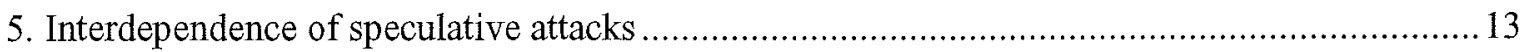

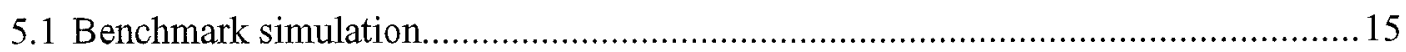

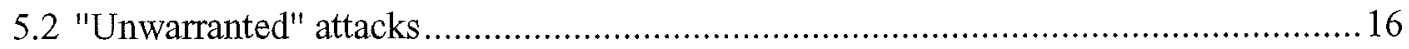

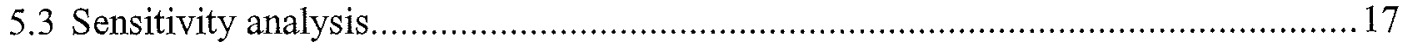

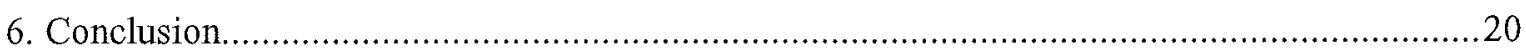

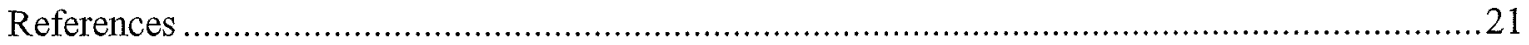




\section{Introduction}

The conduct of monetary policy during the European exchange market turmoil between mid-1992 and mid-1993 was complicated by the tendency for speculative attacks to spread across currencies. For instance, the speculative attack which led to the floating of the Finnish markka on 8th September appeared to trigger speculation against the Swedish krona. Similarly, the forced floating of the Italian lira and the pound sterling in early September and the increased pressure on the French franc appeared to be related. Finally, the abandonment of the Swedish krona's ECU parity on 18th November caused substantial pressure on the parity of the Norwegian krone. Despite considerable, but anecdotal, evidence that speculative attacks are contagious, there appears to be no literature that directly addresses the question of whether and, if so, why speculative attacks tend to spread. This paper attempts to provide an answer to this question.

There are several explanations as to why a successful attack on one parity might lead to increased pressure on another. One explanation focuses on the effects of the collapse of one parity on the fundamentals of another currency. The model presented in this paper falls into this category and emphasises the effects of the collapse of one currency on the competitiveness of economies whose currencies remain pegged. A second explanation relies on the existence of informational asymmetries. When markets do not fully know the extent of monetary authorities' commitment to defend exchange rates, the collapse of one currency may contain information that another parity is likely to collapse. Informational contagion effects might thus occur. A third explanation is based on models with multiple equilibria and self-fulfilling speculative attacks. Eichengreen and Wyplosz (1993) use this paradigm to explain why so many currencies that were pegged to the ECU came under attack in 1992-93. They argue that investors believed that if one or more ERM currencies were devalued or forced to withdraw from the ERM, the process of moving towards monetary union would be derailed. With little prospect of a single currency in the near future, their argument continues, central banks would be tempted to ease monetary policy in an attempt to promote economic growth. By causing the central banks to change their underlying policies, and hence the fundamentals, a speculative attack would thus be self-fulfilling in the sense referred to by Obstfeld (1986). ${ }^{1}$

The present paper is structured as follows. First, the Section 2 provides some empirical evidence of exchange rate contagion using daily interest rate data for Denmark, Norway and Sweden during the foreign exchange turmoil of the autumn of 1992 . We show that interest rate spreads, which capture expected exchange rate changes, increase when other fixed exchange rates collapse. This is consistent with the contagion hypothesis.

1 An alternative interpretation is that investors believed that individual central banks felt that the cost of realigning would be lower if some other central bank realigned first. In this case, one successful speculative attack could cause pressures to develop on many other currencies. This explanation, stressing the importance of the realignment cost, is an example of the first type of contagion. 
In Section 3 we model the contagion process, using a two-country version of the model developed by Flood and Garber (1984) to study speculative attacks and extended by, for example, Willman (1988) to include sticky wages. We assume that both economies operate a fixed exchange rate regime which, depending on the extent to which the central bank extends credit, may collapse. The forced depreciation of one currency in our model has effects on prices and income in the other country through its effect on that country's competitiveness. This makes the collapse times interdependent. In Section 4 we show how to solve for these collapse times.

Since we are unable to provide explicit solutions for the time paths of the macroeconomic variables and for the collapse times, in Section 5 we present the results from numerical simulations. With excessive credit creation in both countries, we show that the collapse of the first exchange rate speeds up the collapse of the second exchange rate. The reason for this is that the collapse of the first currency leads to a real appreciation of the second currency, which depresses income and prices in the second country. This in turn reduces the demand for money and causes a loss of foreign exchange reserves. With lower foreign exchange reserves, the ability to withstand a speculative attack is reduced and the collapse of the second parity accelerated. Perhaps more interestingly, we show that a parity that is sustainable in the absence of an attack on another currency may be attacked in the event of a successful attack on that other currency. This could explain why some currencies that did not seem obviously misaligned were attacked during the autumn of 1992. Finally, in Section 6 we review the most important conclusions.

\section{Some Nordic evidence on contagion}

This section uses data on market-determined interest rates to assess depreciation expectations in the Nordic countries during the exchange market crisis of the autumn of 1992. We first study the behaviour of interest rates in early September, when the Finnish markka, pound sterling and Italian lira were floated and the Spanish peseta was devalued. Next, we turn to the period between mid-November and mid-December when the Swedish krona and the Norwegian krone were floated and the Spanish peseta and the Portuguese escudo were devalued.

Figure 1 contains plots of three-month interest rates in Denmark, Norway and Sweden. ${ }^{2}$ As the chart shows, immediately following the successful speculative attack on the Finnish markka on 8 th September interest rates rose by about $5 \%$ in Sweden and $2 \%$ in Norway. Assuming that market participants believed that a devaluation, if it occurred, would amount to $10 \%$, back-of-the-envelope calculations suggest that after the floating of the Finnish exchange rate the probability of a devaluation during the coming three months increased by

2 For Denmark and Norway we have used Euro-currency rates. Owing to incomplete data, we have used the yield on 90-day Treasury discount notes for Sweden. 
FIGURE 1

THREE-MONTH INTEREST RATES DURING SEPTEMBER 1992

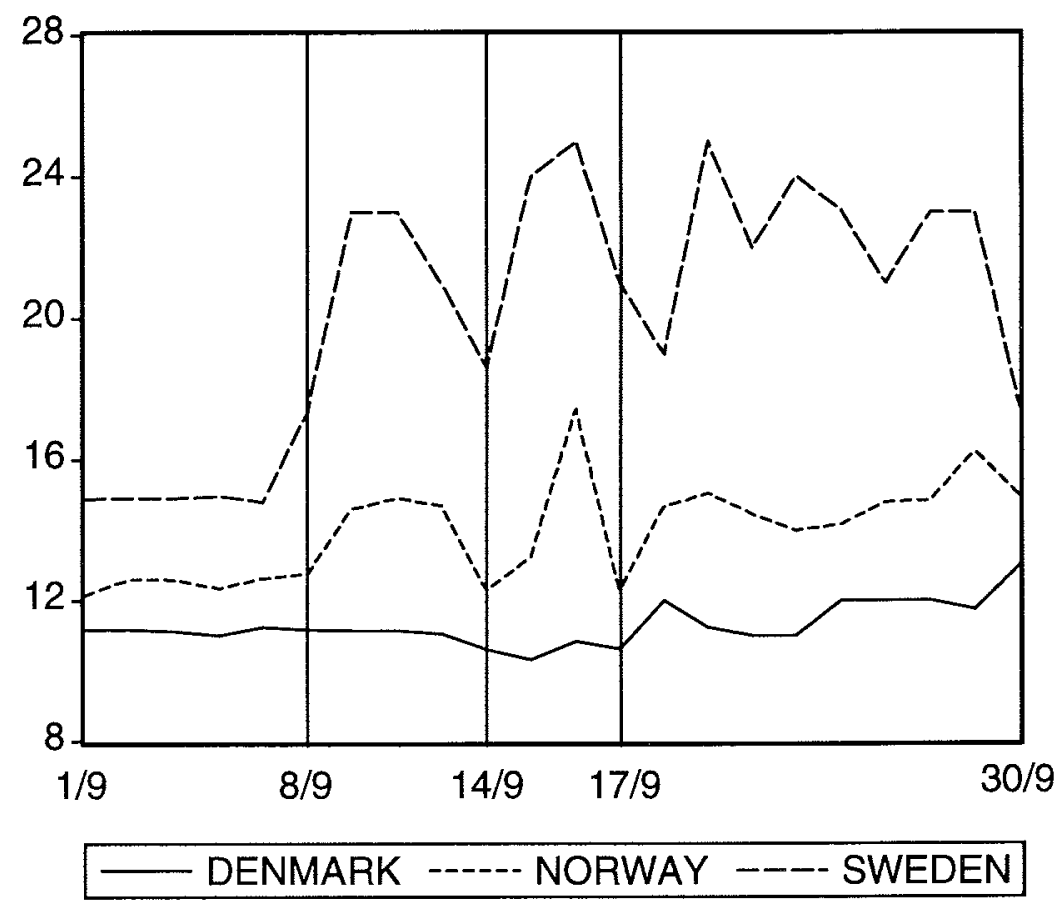

FIGURE 2

THREE-MONTH INTEREST RATES DURING NOVEMBER 1992

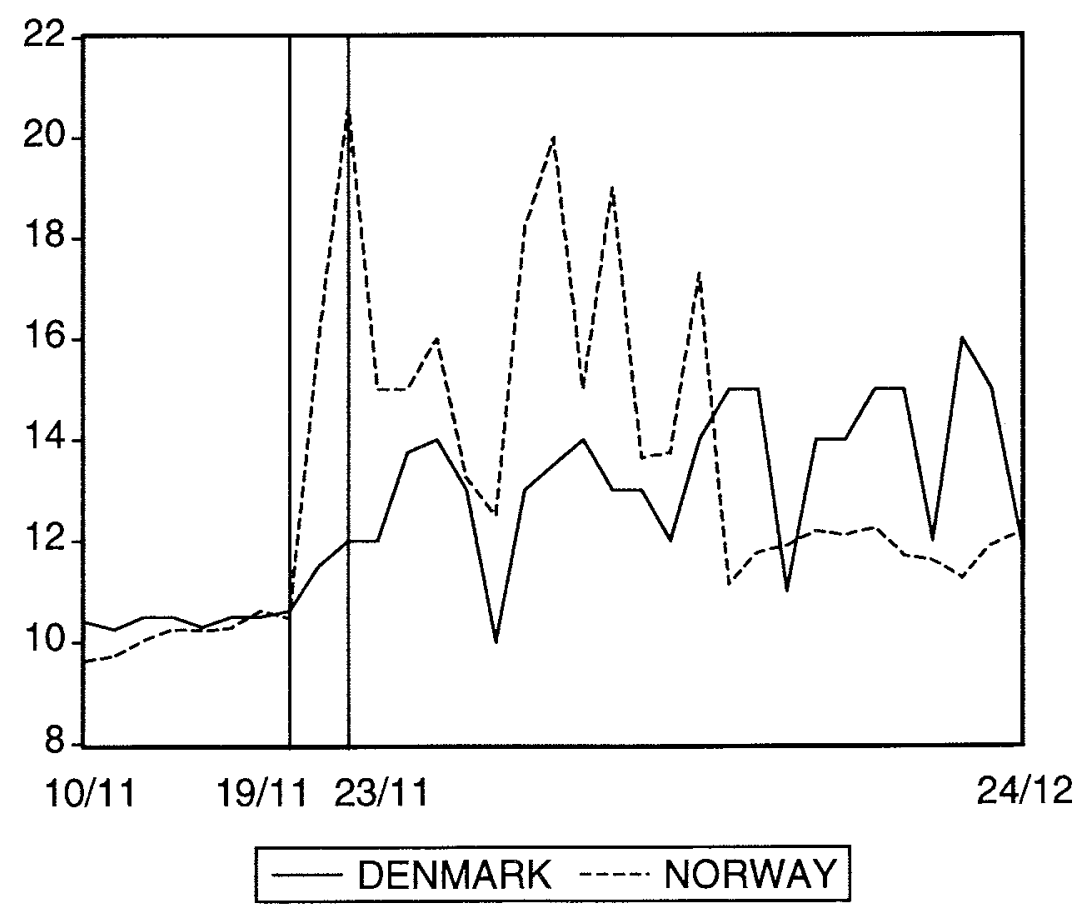


$12 \%$ in Sweden and $5 \%$ in Norway. ${ }^{3}$ These numbers are large enough to be economically relevant.

During the days following the attack on the Finnish parity, the Norwegian interest rate returned to the same level as immediately before the attack. In Sweden, however, the interest rate had still not returned to its earlier level when Italy devalued the lira on 14th September. As can be seen, the Italian devaluation was followed by increased devaluation expectations in the case of the Swedish krona and the Norwegian krone, but not, interestingly, in the case of the Danish krone.

The floating of the lira and the pound sterling and the devaluation of the Spanish peseta on 17 th September are also clearly reflected in the interest rate data, with the Norwegian, Danish and, in particular, Swedish interest rates responding to the turmoil.

In Figure 2 we turn to the behaviour of the Danish and Norwegian interest rates in November and December 1992. The chart suggests that the floating of the Swedish krona on 19th November led to a large increase in the Norwegian interest rate over the next few days, which peaked on 23rd November following the devaluation of the peseta and the Portuguese escudo. The Danish interest rate also rose both after the collapse of the Swedish parity and after the Spanish and Portuguese devaluations. ${ }^{4}$

In sum, we interpret the empirical evidence reviewed above as suggesting that successful speculative attacks lead to pressures on other currencies, that is, contagion is present, and that devaluation probabilities change by economically plausible amounts.

\section{The model}

In this section we describe the model..$^{5}$ All variables, except interest rates, are in natural logarithms. For clarity we disregard uncertainty and employ a deterministic model. We consider two countries, which we refer to as countries $F$ and $S$, and which may be thought of as Finland and Sweden. For simplicity we study the symmetric case where the behavioural parameters, except for the policy variables, are identical in the two countries and suppress time subscripts. We start with the demand for money, which is given by

$$
\mathrm{m}_{i}-\mathrm{p}_{i}=\phi \mathrm{y}_{i}-\gamma \mathrm{r}_{i}, \quad i=\mathrm{F}, \mathrm{S}
$$

3 Suppose that the foreign interest rate is constant. Let $r$ denote the annualised interest rate on 90-day bonds, $\pi$ the probability of a devaluation and $\delta$ the size of the devaluation if it occurs (which we assume to be constant). Uncovered interest parity then implies that $(1+\Delta r)^{1 / 4}-1=\Delta \pi \delta$, which in turn implies that $\Delta \pi=\left((1+\Delta \mathrm{r})^{1 / 4}-1\right) / \delta$.

4 Note, however, that the Norwegian decision to float the krone on 19th December was not associated with an increase in Danish interest rates.

5 The model is based on the standard one-country speculative attack model developed in Flood and Garber (1984) and recently reviewed in Agénor et al. (1992). It has been extended with a real sector as in e.g. Willman (1988). 
where $m$ denotes the money stock, $p$ the price level, $y$ the level of real income and $r$ the nominal interest rate.

Initially both countries peg their currencies to that of a third country (which may be thought of as Germany). We denote the nominal interest rate in the third country by ${ }^{*}$. Uncovered interest parity implies that

(2) $\quad \mathrm{r}_{i}=\mathrm{E} \dot{\mathrm{s}}_{i}+r^{*}$, $i=\mathrm{F}, \mathrm{S}$

where $s_{i}$ denotes the price of one unit of the third currency in terms of currency $i$.

Implicitly, each of the three countries in this model produces a separate good. The domestic price level, $\mathrm{p}_{i}$, is a weighted average of the domestic currency price of the three goods. Assuming that the price of the Finnish and Swedish goods is determined by the wage level in the country of production, the domestic price level is

$$
\mathrm{p}_{i}=\alpha \mathrm{w}_{i}+\varepsilon\left(\mathrm{w}_{j}+\mathrm{s}_{i, j}\right)+(1-\alpha-\varepsilon)\left(\mathrm{s}_{i}+\mathrm{p}^{*}\right), \quad i=\mathrm{F}, \mathrm{S}
$$

where $\mathrm{w}_{i}$ denotes the wage level in country $\mathrm{i}, \mathrm{s}_{i, j}=\mathrm{s}_{i}-\mathrm{s}_{j}$ the cost of one unit of currency $j$ in terms of currency $i, \mathrm{p}^{*}$ the price of the third-country good, and $\alpha$ and $\varepsilon$ the weights of the competing Finnish and Swedish goods in the consumption basket. This model reduces to the standard speculative attack model if $\alpha=\varepsilon=0 .{ }^{6}$

Next we turn to the behaviour of wages. Since Sweden and Finland produce competing goods and since there are no real disturbances, in the steady state unit labour costs must be identical. In the short run, however, goods market arbitrage is imperfect and wages are sticky, so that unit labour costs may differ in the two countries. We assume that the rate of change of nominal wages depends on some measure of core inflation and on the output gap,

$$
\dot{\mathrm{w}}_{i}=\mathrm{c}_{i}+\psi\left(\mathrm{y}_{i}-\bar{y}\right), \quad i=\mathrm{F}, \mathrm{S}
$$

where $\psi$ measures the speed of adjustment of wages to excess demand. If $\psi$ is infinity real wages adjust instantaneously and output always equals potential output. Furthermore, we assume that core inflation adjusts only sluggishly to actual inflation,

$$
\dot{\mathrm{c}}_{i}=\delta\left(\dot{\mathrm{p}}_{i}-\mathrm{c}_{i}\right), \quad i=\mathrm{F}, \mathrm{S}
$$

6 See Flood and Garber (1984). 
where $\delta$ measures the sensitivity of core inflation to actual inflation: the larger the value of $\delta$, the faster wages adjust to changes in inflation. Note that in the steady state nominal wage growth and core and actual inflation are equal. Finally, we assume that aggregate demand for the domestic good is inversely related to the real exchange rate.

$$
\mathrm{y}_{i}=\beta\left(\mathrm{s}_{i, j}-\mathrm{w}_{i}+\mathrm{w}_{j}\right), \quad i \neq j \text { and } i, j=\mathrm{F}, \mathrm{S}
$$

To interpret (6), note that, as in (3), $\mathrm{s}_{i, j}+\mathrm{w}_{j}$ denotes the wage level in country $j$ expressed in terms of currency $i$. The parameter $\beta$ captures the degree of substitutability of the Swedish and Finnish goods. If $\beta=\infty$, Swedish and Finnish goods are perfectly substitutable and the law of one price holds.

Turning to the monetary side of the model, we assume for simplicity that the money multiplier is constant (and normalised to zero) so that the money supply equals the sum of central bank holdings of domestic assets, $D_{i}$, and the domestic currency value of the foreign exchange reserves, $\mathrm{R}_{i}$. The following equation is a log-linear approximation to this identity:

$$
\mathrm{m}_{i}=\eta D_{i}+(1-\eta) R_{i}, \quad i=\mathrm{F}, \mathrm{S}
$$

where $\eta$ denotes the equilibrium fraction of the central bank's assets that is held in the form of domestic assets. We close the model with the standard assumption that domestic credit growth is exogenously determined and is given by

$$
\dot{\mathrm{D}}_{i}=\mu_{i}, \quad i=\mathrm{F}, \mathrm{S}
$$

In this model, as in most speculative attack models, the fundamental cause of the speculative attack is the continued excessive credit creation by the central bank. Of course, we do not mean to argue that this was the cause of the speculative attacks in 1992 and 1993. Our concern is how a speculative attack spreads once it has started, and not its initial cause. Thus we adopt the excessive credit creation explanation merely for convenience. ${ }^{7}$

\section{Solution}

In this section we solve the model for the time path of international reserves when the exchange rate is fixed and show how to determine the collapse times.

7 For a survey of models which explicitly derive a government's decision to devalue, see e.g. Obstfeld (1994). 
Note that under perfect foresight, $\dot{\mathrm{s}}_{i}=\dot{\mathrm{s}}_{i}$. Setting $\overline{\mathrm{y}}=i^{*}=\mathrm{p}^{*}=0$ and combining equations (1), (2) and (3) we obtain

$$
\mathrm{m}_{i}=\alpha \mathrm{w}_{i}+\varepsilon\left(\mathrm{w}_{j}-\mathrm{s}_{j}\right)+(1-\alpha) \mathrm{s}_{i}+\phi \mathrm{y}_{i}-\gamma \dot{\mathrm{s}}_{i}, \quad i=\mathrm{F}, \mathrm{S}
$$

Under fixed exchange rates the central bank accommodates any change in the domestic demand for money through the purchase or sale of international reserves. Setting $\mathrm{s}_{i}=\overline{\mathrm{s}}_{i}$ (where $\overline{\mathrm{s}}_{i}$ is the fixed exchange rate level) and $\dot{\mathrm{s}}_{i}=0$, equation (9) then determines the evolution of international reserves. To see this, substitute equations (6), (7) and (8) in (9) and solve for $\mathrm{R}_{i}$.

$$
\mathrm{R}_{i}(t)=\frac{(1-\alpha) \bar{s}_{i}-\eta \mathrm{D}_{0 i}}{1-\eta}-\frac{\eta}{1-\eta} \mu_{i} t+\frac{\alpha}{1-\eta} \mathrm{w}_{i}(t)+\frac{\varepsilon}{1-\eta}\left(\mathrm{w}_{j}(t)-\overline{\mathrm{s}}_{j}\right)+\frac{\phi}{1-\eta} \mathrm{y}_{i}(t)
$$

Equation (10) indicates that the stock of reserves falls over time as the central bank expands credit $\left(\mu_{i}>0\right)$. Furthermore, the stock of reserves depends positively on the price of the Swedish and Finnish goods as determined by Swedish and Finnish wages, exchange rates and domestic output. With both countries fixing their exchange rates against the Deutsche Mark and the goods markets initially in equilibrium -- that is, with output gaps and inflation equal to zero -the wage and output levels in both countries are fixed and the demand for money is constant. The credit creation in the two countries therefore leads to losses of foreign exchange reserves at a rate proportional to the rate of domestic credit creation. As a result the (finite) stock of foreign exchange reserves will be depleted after a period of time. We follow the literature and assume that there is some lower limit $\bar{R}$, say zero, beyond which the monetary authorities will no longer be willing to defend the currency peg. Thus, once $\bar{R}$ is reached the monetary authorities will let the exchange rate float.

We assume that the rate of credit creation in Finland is higher than in Sweden, which, given the assumption that the two economies are otherwise identical, implies that the speculative attack on the Finnish markka occurs before the attack on the Swedish krona. We therefore have to consider three separate regimes (rather than two as in the standard speculative attack literature); in the first regime both currencies are pegged to the Deutsche Mark; in the second regime, the Finnish markka is floating after being attacked and the Swedish krona remains pegged; and in the third regime both currencies are floating after the Swedish krona is attacked.

To see why contagion occurs, note from equation (10) that international reserves in Sweden depend on Swedish wages and output and on the Finnish exchange rate. A depreciation of the Finnish markka reduces the Swedish demand for money and consequently the level of 
international reserves in two different ways. First, the depreciation reduces the prices of Finnish goods in Sweden and thereby the Swedish price level. Secondly, since wages are sticky, the floating of the Finnish markka leads to a loss of competitiveness in Sweden. The resulting deflationary pressures on wages and output also reduce the demand for money, which in turn leads to capital outflows and reserve losses. In sum, the collapse of the Finnish parity reduces the demand for money in Sweden and thereby speeds up the collapse of the Swedish parity.

\subsection{Collapse times}

Next, we follow Flood and Garber (1984) to determine the collapse times by using the traditional no-arbitrage condition that at the moment of the collapse the exchange rate cannot jump. ${ }^{8}$ Before doing so, however, we need to solve for the time path of the exchange rates in each regime.

We start by solving the system of differential equations in the third regime, in which both currencies are floating and international reserves are zero. Substituting equations (6), (7) and (8) in (9) and solving for $\dot{s}_{i}$ gives two equations determining the changes in the forward-looking exchange rates. Substituting equation (6) in equation (4) gives another two equations determining the change in nominal wages in both countries. Finally, equation (3) and the first four equations of our system can be used to derive the last two equations determining the change in core inflation. Together this gives the following system of differential equations (11) on page 11 .

The state matrix of the system of differential equations (11) has four negative and two positive eigenvalues. Using the transversality conditions to rule out divergent paths, we obtain the general solution of the homogenous system with four constants of integration. Using the method of undetermined coefficients we can also find a particular solution to the nonhomogenous system. Adding the two together leads to the following general solution:

$$
\left[\begin{array}{c}
\mathrm{s}_{F}^{3} \\
\mathrm{~s}_{S}^{3} \\
\mathrm{w}_{F}^{3} \\
\mathrm{w}_{S}^{3} \\
\mathrm{c}_{F}^{3} \\
\mathrm{c}_{S}^{3}
\end{array}\right]=\left[\begin{array}{c}
\eta\left(\mathrm{D}_{F 0}+\gamma \mu_{F}\right) \\
\eta\left(\mathrm{D}_{S 0}+\gamma \mu_{S}\right) \\
\eta\left(\mathrm{D}_{F 0}+\gamma \mu_{F}\right) \\
\eta\left(\mathrm{D}_{S 0}+\gamma \mu_{S}\right) \\
\eta \mu_{F} \\
\eta \mu_{S}
\end{array}\right]+\left[\begin{array}{c}
\eta \mu_{F} \\
\eta \mu_{S} \\
\eta \mu_{F} \\
\eta \mu_{S} \\
0 \\
0
\end{array}\right] t+\sum_{k=1}^{4} \overrightarrow{\mathrm{A}}_{k} \mathrm{~A}_{k} \mathrm{e}^{\rho k^{t}}
$$

8 Of course, this arbitrage condition hinges on our assumption of perfect foresight. 


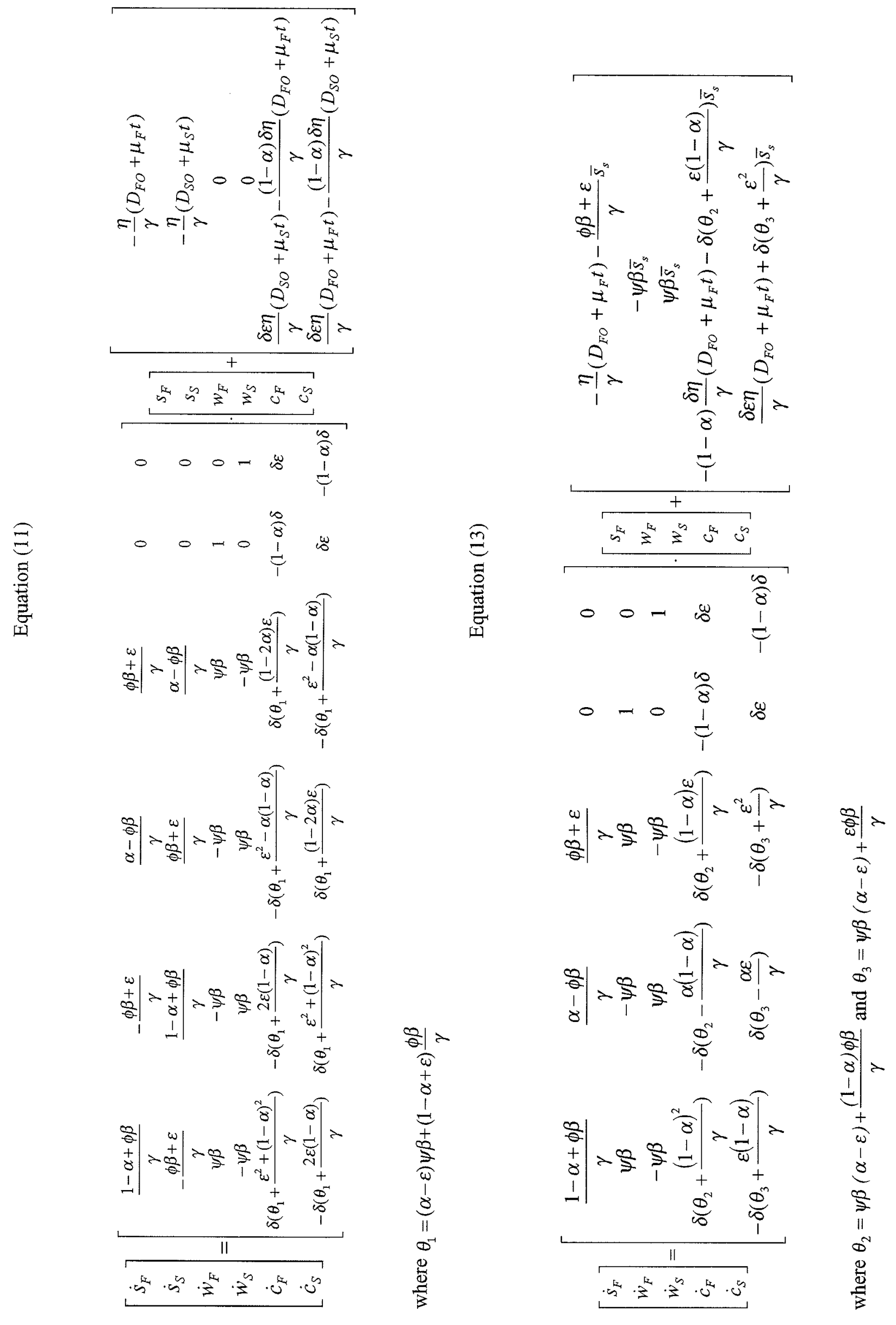


where superscript 3 denotes the third regime and $\vec{A}_{k}$ is the eigenvector corresponding to the negative eigenvalues $p_{k}$ of the state matrix of system (11). The four constants of integration $A_{k}$ are determined by the four initial conditions for the Swedish and Finnish wage levels and core inflation. Note that along the steady state path nominal wages and exchange rates grow at a rate proportional to the rate of domestic credit creation. Thus, in the long run the nominal exchange rate regime does not matter for real competitiveness between the two countries.

Next we solve for the paths of exchange rates and wages in the second regime, in which the Finnish markka is floating but the Swedish krona remains pegged at the level $\bar{s}_{S}$. The equations of motion are the same as before, except that $s_{S}^{2}=\bar{s}_{S}$ and $\dot{s}_{S}=0$. Furthermore, the Finnish foreign exchange reserves have been depleted in the speculative attack and equal zero. The Swedish foreign exchange reserves, however, are positive, but decreasing according to equation (10). This reduces the system in the second regime to the five equation system (13) on the previous page.

The state matrix of system (13) has four negative and one positive eigenvalue. We use the same techniques as above to find the paths of exchange rates and wages. This results in the following equations:

$$
\left[\begin{array}{c}
\mathrm{s}_{F}^{2} \\
\mathrm{w}_{F}^{2} \\
\mathrm{w}_{S}^{2} \\
\mathrm{c}_{F}^{2} \\
\mathrm{c}_{S}^{2}
\end{array}\right]=\left[\begin{array}{c}
\eta\left(\mathrm{D}_{F 0}+\gamma \mu_{F}\right) \\
\eta\left(\mathrm{D}_{F 0}+\gamma \mu_{F}\right) \\
\overline{\mathrm{s}}_{S} \\
\eta \mu_{F} \\
0
\end{array}\right]+\left[\begin{array}{c}
\eta \mu_{F} \\
\eta \mu_{F} \\
0 \\
0 \\
0
\end{array}\right] \cdot \mathrm{t}+\sum_{l=1}^{5} \overrightarrow{\mathrm{B}}_{l} \mathrm{~B}_{l} \mathrm{e}^{\lambda_{l} t}
$$

where $\vec{B}_{l}$ is the eigenvector corresponding to the eigenvalues $\lambda_{1}$ of the state matrix and $B_{1}$ represents the constants of integration to be determined. The superscript 2 denotes second regime variables.

Turning to the first regime, we assume that the goods market is in equilibrium so that wages are fixed and core and actual inflation are equal to zero. The demand for money is therefore fixed in both countries. The growth of domestic credit thus leads to a gradual depletion of the central bank's foreign exchange reserves. Using equations (12) and (14) we can then determine the two collapse times using the condition that the exchange rate cannot jump at the time of the collapse, that is,

$$
\begin{gathered}
\mathrm{s}_{S}^{3}\left(\mathrm{t}_{S}\right)=\overline{\mathrm{s}}_{S} \\
\mathrm{~s}_{F}^{2}\left(\mathrm{t}_{F}\right)=\overline{\mathrm{s}}_{F}
\end{gathered}
$$


where $t_{S}$ and $t_{F}$ denote, respectively, the times of the speculative attacks against the Swedish krona and the Finnish markka. Equations (15) and (16), however, depend on the nine constants of integration $A_{k}$ and $B_{1}$, which are determined by eight initial conditions for wages and core inflation and one terminal condition, which states that at the time of the Swedish collapse the Finnish exchange rate cannot jump. ${ }^{9}$

$$
\begin{aligned}
& \mathrm{w}_{F}^{2}\left(\mathrm{t}_{F}\right)=\mathrm{w}_{F}^{1} \\
& \mathrm{w}_{S}^{2}\left(\mathrm{t}_{F}\right)=\mathrm{w}_{S}^{1} \\
& \mathrm{c}_{F}^{2}\left(\mathrm{t}_{F}\right)=\mathrm{c}_{F}^{1} \\
& \mathrm{c}_{S}^{2}\left(\mathrm{t}_{F}\right)=\mathrm{c}_{S}^{1}
\end{aligned}
$$

$$
\begin{aligned}
& \mathrm{w}_{F}^{3}\left(\mathrm{t}_{S}\right)=\mathrm{w}_{F}^{2}\left(\mathrm{t}_{S}\right) \\
& \mathrm{w}_{S}^{3}\left(\mathrm{t}_{S}\right)=\mathrm{w}_{S}^{2}\left(\mathrm{t}_{S}\right) \\
& \mathrm{c}_{F}^{3}\left(\mathrm{t}_{S}\right)=\mathrm{c}_{F}^{2}\left(\mathrm{t}_{S}\right) \\
& \mathrm{c}_{S}^{3}\left(\mathrm{t}_{S}\right)=\mathrm{c}_{S}^{2}\left(\mathrm{t}_{S}\right)
\end{aligned}
$$$$
\mathrm{s}_{F}^{3}\left(t_{S}\right)=\mathrm{s}_{F}^{2}\left(\mathrm{t}_{S}\right)
$$

Equations (15) to (25) simultaneously determine the two collapse times and the nine constants of integration. The resulting system of eleven equations in eleven unknowns cannot be solved explicitly. In the next section we therefore present numerical simulations which allow us to examine the effect of different parameter configurations on the collapse times. ${ }^{10}$

\section{Interdependence of speculative attacks}

In order to simulate the model we need to assume values for the structural parameters. The benchmark simulation presented in Figure 3 is based on the following parameter values. The two most critical parameters are the degrees of nominal and real wage flexibility. In the benchmark scenario we assume that $\psi$, the elasticity of real wages with respect to the output gap, is $0.1 .^{11}$ Furthermore, $\delta$, which captures the speed with which nominal wages adjust to current inflation, equals $0.1 .^{12}$

Turning to the other parameters in the model, we assume that the rate of domestic credit creation in Finland is double the rate of credit creation in Sweden $\left(\mu_{\mathrm{F}}=0.10, \mu_{\mathrm{S}}=0.05\right)$;

9 The latter condition is a standard condition in solving perfect foresight models with switching regimes. See e.g. Obstfeld and Stockman (1985).

10 Assuming fixed nominal wages (e.g. by setting $\delta$ and either $\psi$ or $\beta$ equal to zero) allows us to reduce the system of equations to one and two differential equations respectively in the second and third regime. In that case the Swedish collapse time can be solved analytically. While this model can be considered as a limiting case of the full model (the results of which appear in scenarios 13 and 14 of Table 1), we do not analyse it because with nominal wages fixed, a higher rate of domestic credit creation in Finland than in Sweden leads to permanently falling unit labour costs in Finland and a permanently increasing output gap in Sweden.

11 Estimates of $\psi$ are reported in Bini Smaghi and Vori (1993). For European countries they lie between 0.4 for Italy and 0.1 for Denmark.

12 This implies that it takes about 7 units of time for half of a change in inflation to be reflected in nominal wages. 


\section{FIGURE 3 \\ THE BENCHMARK CASE}

\section{EXCHANGE RATES}
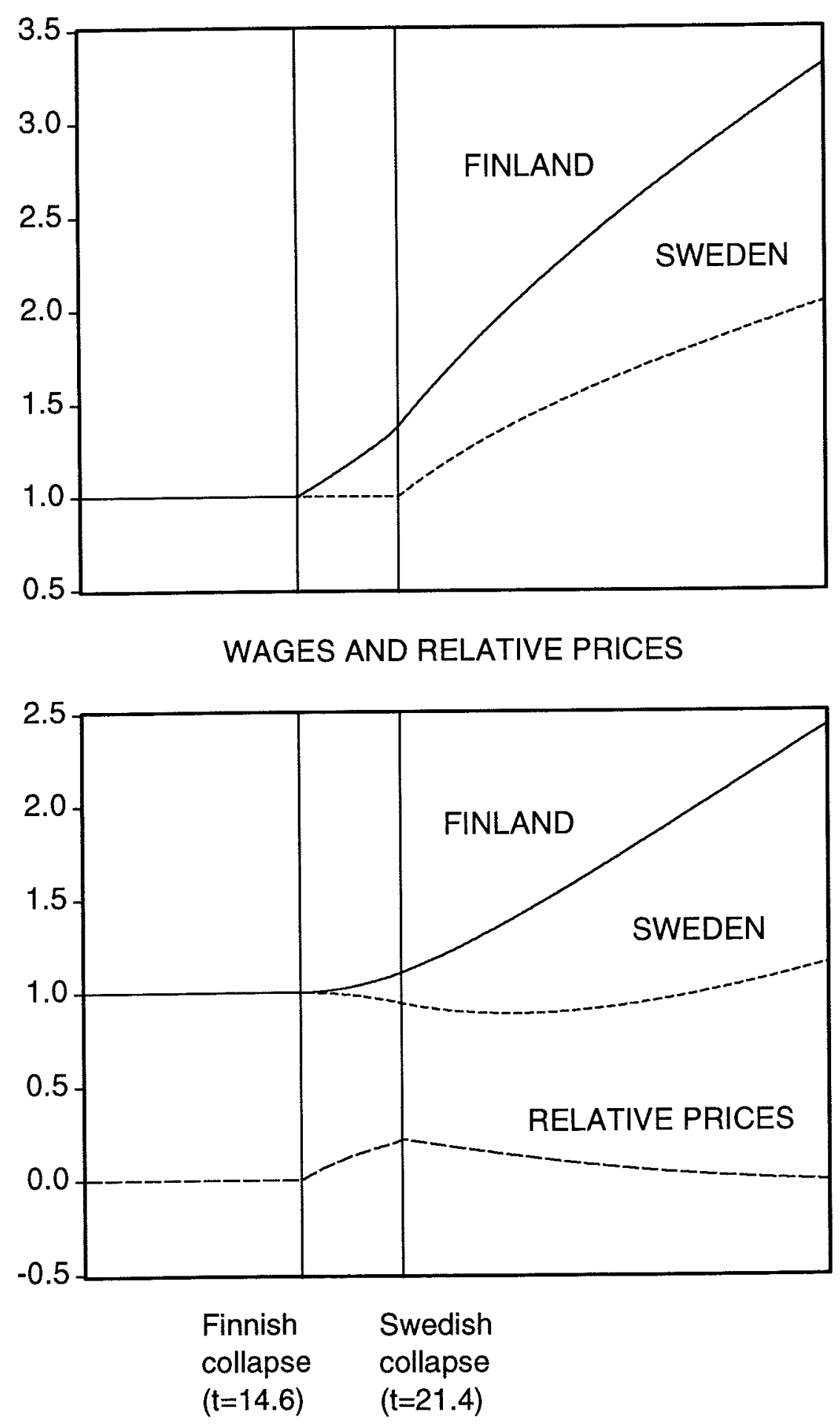
that both countries peg the exchange rate at the same level $\left(\overline{\mathrm{s}}_{S}=\overline{\mathrm{s}}_{F}=1\right)$; and that initially they have the same level of foreign exchange reserves $\left(D_{F 0}=D_{S 0}=0.5\right)$. Furthermore, we assume that $\beta$, the elasticity of aggregate demand with respect to competitiveness between the two countries, is 0.5 , and that $\alpha$ and $\varepsilon$, which capture the weights of the domestic and foreign goods in the consumer price indices in the two countries, are, respectively, 0.4 and 0.2 . The income elasticity of money demand, $\phi$, equals unity, the interest rate semi-elasticity of the demand for money, $\gamma$, equals 0.5 and the equilibrium share of domestic credit in the money supply, $\eta$, equals 0.5 throughout the whole exercise. ${ }^{13}$

\subsection{Benchmark simulation}

As Figure 3 illustrates, the no-arbitrage condition implies that there is no instantaneous loss of Swedish competitiveness when the Finnish parity collapses (panel C). Since credit in Finland continues to grow after the collapse of the markka, the exchange rate starts to depreciate after the speculative attack (panel A). With nominal wages in Finland adjusting sluggishly to the increased rate of inflation (panel B), the price of Finnish goods in the Swedish currency consequently falls, which reduces consumer prices and the demand for money in Sweden. Falling unit labour costs in Finland also lead to a gradual loss of Swedish competitiveness (panel C). This loss of Swedish competitiveness has two effects on the demand for Swedish money: (i) it reduces output; and (ii) Swedish wages and prices start to decline under the pressure of the increasing output gap and unemployment (panel B). Both effects reduce the demand for money and accelerate the loss of foreign exchange reserves and the timing of the speculative attack on the Swedish currency.

To assess how the Finnish collapse speeds up the timing of the Swedish collapse, compare the benchmark case with the case in which the rate of credit creation is the same in the two countries (scenario 1 in Table 1). Since the two exchange rates collapse at the same time, there are no contagion effects. In this second simulation the Swedish parity collapses at time 29 , rather than time 21 in the benchmark scenario, the difference being the contagion effect. Before proceeding, note that the contagion merely expedites the collapse of the Swedish currency, since with excessive credit creation the Swedish parity would ultimately have collapsed in any case. We show below that a speculative attack on the Finnish markka can also trigger a speculative attack on the Swedish krona that would otherwise not have occurred.

The relative importance of the price effects versus the effect of the reduction in output on Swedish money demand can be assessed by comparing the benchmark scenario with the second scenario in Table 1 , in which the income elasticity of money demand, $\phi$, equals zero. The Swedish collapse now occurs at time 23, so that more than two-thirds of the acceleration of the Swedish collapse from time 29 to 21 is due to the effect of falling prices on money demand.

13 For some estimates of the interest rate semi-elasticity of money demand, see e.g. Goldfeld and Sichel (1990). 
Table 1

Some deviations from the benchmark scenario

\begin{tabular}{|c|c|c|}
\hline Scenarios $^{*}$ & Finnish collapse time & Swedish collapse time \\
\hline 0) Benchmark & 14.53 & 21.31 \\
\hline 1) $\mu_{\mathrm{F}}=0.05 \ldots \ldots \ldots \ldots$ & 28.82 & 28.82 \\
\hline 2) $\phi=0, \ldots \ldots \ldots \ldots \ldots$ & 14.19 & 23.31 \\
\hline 3) $\mu_{S}=0.10 \ldots \ldots \ldots$ & 13.82 & 13.82 \\
\hline 4) $\mu_{F}=0.05, D_{F O}=0.8 \ldots \ldots$ & 23.53 & 26.69 \\
\hline 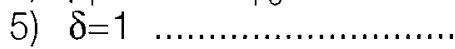 & 14.51 & 27.56 \\
\hline 6) $\delta=0.01 \ldots \ldots$. & 14.53 & 20.55 \\
\hline 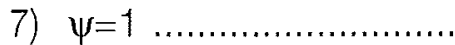 & 14.47 & 22.56 \\
\hline 8) $\psi=0.01 \ldots \ldots \ldots \ldots \ldots \ldots \ldots \ldots \ldots \ldots \ldots \ldots \ldots$ & 14.54 & 21.00 \\
\hline 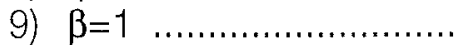 & 14.67 & 20.65 \\
\hline 10) $\beta=0$ & 14.18 & 23.74 \\
\hline 11) $\alpha=0.2, \varepsilon=0.1 \ldots \ldots \ldots \ldots$ & 14.60 & 23.95 \\
\hline 12) $\alpha=0.6, \varepsilon=0.3 \ldots \ldots$ & 14.38 & 16.73 \\
\hline 13) $\beta=0, \delta=0$ & 14.16 & 22.62 \\
\hline 14) $\varepsilon=0, \alpha=0.6, \psi=0, \delta=0$ & 14.44 & 20.76 \\
\hline
\end{tabular}

* Only the values of the parameters that deviate from the benchmark scenario are given.

Next, we turn to the question of how an increase in the Swedish credit growth rate, which expedites the Swedish collapse, affects the Finnish collapse time. In scenario 3 of Table 1 we assume that the rate of credit creation in Sweden doubles to 0.10 , so that it equals the credit growth rate in Finland. As can be seen, the higher rate of credit expansion in Sweden speeds up the collapse of the Finnish currency. The reason for this is as follows. Financial markets foresee that the acceleration of the collapse of the Swedish currency will reduce the prices of Swedish goods in Finland, which tends to reduce inflationary pressure in Finland. This reduces the expected future demand for the Finnish money stock, which in turn accelerates the collapse of the Finnish exchange rate.

We end this section by concluding that the two collapse times are interdependent. In particular, the sooner the Finnish peg collapses, the earlier the Swedish parity will collapse, despite the fact that monetary policy in Sweden (as measured by credit growth) remains unchanged.

\section{2}

\section{"Unwarranted" attacks}

So far we have shown how the timing of the collapse of the Finnish parity affects the timing of an unavoidable speculative attack on Sweden. This leads to the interesting question of whether the collapse of one parity can lead to a speculative attack on another parity that otherwise would not have occurred. To address this question, we assume that the growth rate of credit in Sweden is zero, which implies that in the absence of a Finnish collapse the fixed exchange rate regime for the Swedish krona is viable. Figure 4 shows that despite this, the Finnish collapse leads to a collapse of the Swedish parity. The economic forces behind the 
contagion are the same as above. The Finnish depreciation leads to falling prices and output in Sweden, which in turn leads to a reduction of Swedish money demand and reserve losses. If foreign exchange reserves are "small", the fixed exchange rate regime may collapse. Clearly, Sweden is more vulnerable to contagion the lower the level of its foreign exchange reserves, the greater the effect of the Finnish markka depreciation on Swedish competitiveness and the more the demand for the Swedish currency falls in response to the Finnish depreciation. In Figure 4 we assume that the initial level of foreign exchange reserves in Sweden is only 0.1 and there is considerable real wage rigidity, which leads to significant real effects of the depreciating Finnish markka on Swedish competitiveness. As a result of the Finnish collapse at time 8.9, Swedish competitiveness deteriorates substantially (panel C), leading to a loss of reserves and a collapse of the parity at time 18.5. This case illustrates that the ability of a central bank to fix its exchange rate unilaterally is limited when close trading partners operate under floating exchange rates and let their currencies depreciate. In the long run the Swedish exchange rate returns to its initial pegged level. In the meantime, however, significant costs in terms of unemployment might be incurred.

In the examples above a different growth rate of domestic credit explains the different timing of the speculative attacks on the two currencies. Alternatively we can study the effects of different levels of international reserves and different exchange rate parities on the timing and interdependence of speculative attacks. In scenario 4 of Table 1 we assume that the rate of credit creation in both countries is equal $\left(\mu_{F}=\mu_{S}=0.05\right)$, but the initial stock of international reserves is smaller in Finland than in Sweden $\left(\mathrm{D}_{F 0}=0.8\right.$ and $\left.\mathrm{D}_{S 0}=0.5\right)$. As a result, the Finnish peg collapses sooner (at time 23.5 instead of at time 28.8), which again accelerates the timing of the Swedish collapse (at time 26.6 instead of at time 28.8). The transmission mechanism is the same as before: an early collapse of the Finnish peg leads to deteriorating Swedish competitiveness, which reduces prices and incomes (and thereby money demand), which in turn leads to reserve losses in Sweden. Similar effects on the Swedish collapse time also follow if the Finnish authorities peg their exchange rate below the Swedish peg.

\subsection{Sensitivity analysis}

The above examples illustrate the interdependencies of the speculative attacks in our model. We examine below the sensitivity of these results to variations in some of the parameters.

Scenarios 5 and 6 in Table 1 show the effects of a change in the sensitivity of nominal wages with respect to inflation. Note that if nominal wages are perfectly flexible, the depreciation of the Finnish markka following the attack leads to an immediate increase in Finnish nominal wages and inflation. As a result Finnish real wages are not affected and Swedish competitiveness does not deteriorate. In that case the collapse of the Finnish currency does not increase capital outflows from Sweden and consequently has no effect on the timing of 
FIGURE 4

"UNWARRANTED" CONTAGION

EXCHANGE RATES

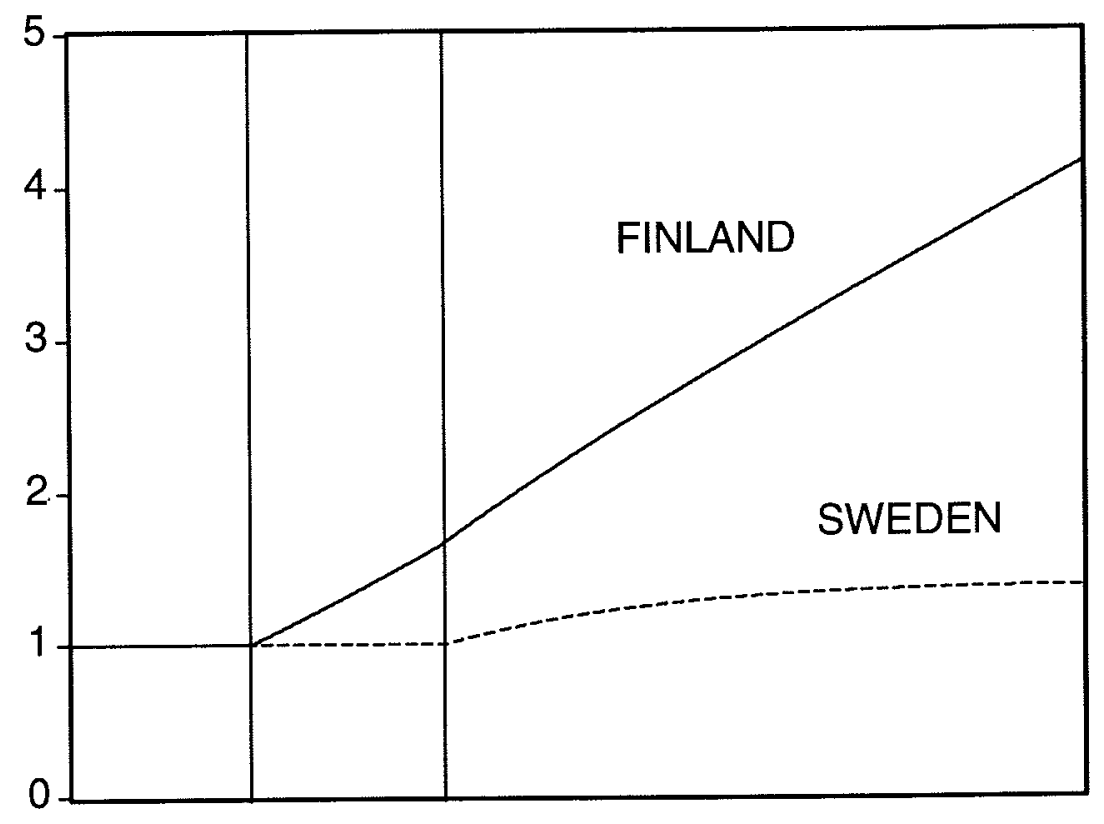

WAGES AND RELATIVE PRICES

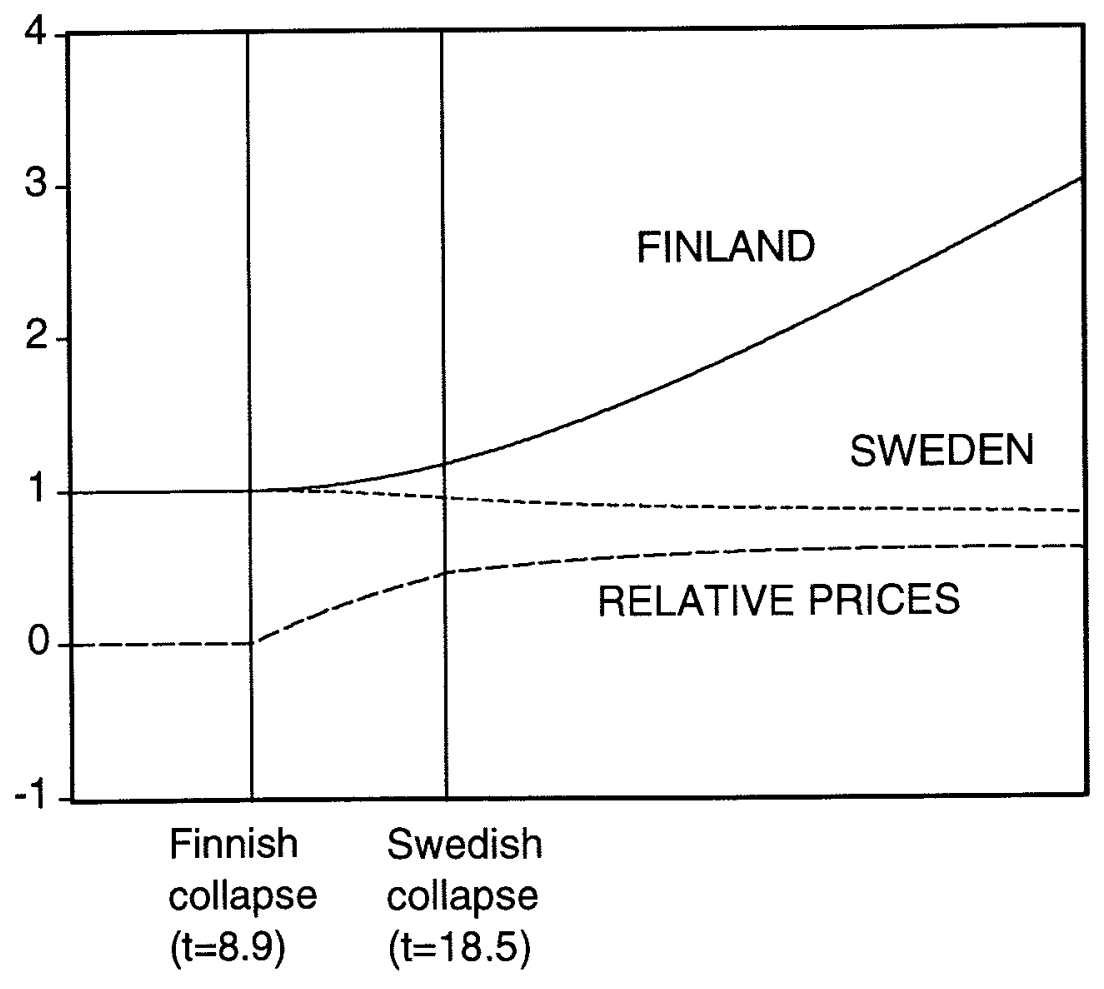


the speculative attack. However, if wages do not adjust immediately to increases in inflation, the depreciation of the Finnish markka following the collapse reduces the Swedish currency price of the Finnish good and takes the form of a competitive depreciation which depresses prices and economic activity in Sweden. Scenarios 5 and 6 illustrate that a low degree of nominal wage flexibility thus leads to increased pressure on the Swedish exchange rate.

Scenarios 7 and 8 in Table 1 show the effect of a change in the sensitivity of real wages to the output gap. Higher real wage flexibility accelerates the attack on the Finnish markka, but delays the attack on the Swedish currency. The first result is familiar from traditional speculative attack models. ${ }^{14}$ The second one requires rather more explanation. For a given real exchange rate deterioration a faster speed of adjustment leads to more rapidly declining wages in Sweden, and hence larger capital outflows. This accelerates the attack. However, because of our assumption that the Finnish and Swedish economies are structurally identical, higher real wage flexibility also increases the adjustment of Finnish wages, which consequently limits the loss of Swedish competitiveness and reduces the necessary adjustment of wages and output and its effect on Swedish money demand. This latter effect dominates in scenarios 7 and 8 .

A higher degree of substitutability between Finnish and Swedish goods, as captured by a greater sensitivity of aggregate demand to relative competitiveness, has ambiguous results on the timing of speculative attacks. On the one hand, the effects are similar to those of increased real wage flexibility. On the other hand, it increases the effect of a deterioration in competitiveness on output and money demand. One would expect the second effect to dominate, which is indeed the case in scenarios 9 and 10. The more substitutable Finnish and Swedish goods are, the greater the contagion effects. In scenario $10(\beta=0)$, the improved competitiveness of Finnish producers has no effect on Swedish output. In this case Finnish and Swedish goods are complements, and contagion occurs only through a pure price effect. However, the contagion is still substantial.

Finally, we review the effects of a change in the share of third-country goods in the consumption basket of Finnish and Swedish consumers (scenarios 11 and 12). The results indicate that a higher share of domestic goods in domestic consumption will accelerate the collapse of both currencies. This effect is particularly strong for the timing of the Swedish collapse because it reinforces the contagion effect in two ways. On the one hand, a high share of domestic goods limits the inflationary effects of a depreciation in Finland and leads to much improved Finnish competitiveness. On the other hand, the effects of deteriorating Swedish competitiveness on Sweden's domestic price level will be stronger.

14 See, for example, the analysis of the effects of sticky wages (both forward-looking and backwardlooking) on the timing of a speculative attack in Willman (1988) and Willman (1992). 


\section{Conclusion}

This paper presents a model which can partially explain the contagion effects of speculative attacks against fixed exchange rate regimes. We show how the forced depreciation of one currency affects the competitiveness of countries whose currencies are still pegged, and that this increases the speculative pressure and speeds up their collapse. Even if the currency peg is otherwise viable, these contagion effects can trigger a speculative attack and force the depreciation of the currency in question. We also show that the contagion effects in our model are stronger the lower the degree of real and nominal wage flexibility, the higher the degree of trade integration between the two countries and the less integrated the two countries are with the anchor country.

The model contributes to our understanding of the recurrent foreign exchange crises that affected Europe between August 1992 and August 1993. It explains why the speculative pressure on the exchange rate parity increased in countries which are closely integrated with a country whose exchange rate parity was successfully attacked. In this paper we have focused on the experience of the Nordic countries. Similar contagion effects were, however, experienced by Portugal when the Spanish peseta was devalued and by Ireland when the pound sterling was floated. The model also has important policy implications: the fact that speculative attacks may spread, in particular to currencies that would not otherwise be attacked, suggests that a coordinated response by the central banks under attack is appropriate. 


\section{References}

Agénor, P. R., J. S. Bhandari and R. P. Flood (1992): "Speculative attacks and models of balance of payments crises". IMF Staff Papers, 39, 357-94.

Bini Smaghi, L. and S. Vori (1993): "Rating the EC as an optimal currency area". Temi di discussione del Servizio Studi, 187, Banca d'Italia.

Eichengreen B. and C. Wyplosz (1993): "The unstable EMS". Brookings Papers of Economic Activity, No. 1, 51-143.

Flood, R. and P. Garber (1984): "Collapsing exchange-rate regimes: some linear examples". Journal of International Economics, 17, 1-13.

Goldfeld, S. and D. Sichel (1990): "The demand for money", in B. Friedman and F. Hahn (eds.), Handbook of monetary economics. (North Holland, Amsterdam).

Goldstein, M., D. Folkerts-Landau, P. Garber, L. Rojas-Suárez and M. Spencer (1993): "International Capital Markets: Part 1. Exchange Rate Management and International Capital Flows". World Economic and Financial Surveys, IMF.

Obstfeld, M. (1986): "Rational and self-fulfilling balance-of-payments crises". American Economic Review, 76, 72-81.

Obstfeld, M. (1994): "The logic of currency crises". NBER Working Paper 4640.

Obstfeld, M. and A. C. Stockman (1985): "Exchange rate dynamic", in R. W. Jones and P. B. Kenen (eds.), Handbook of international economics, 1. (North Holland, Amsterdam).

Willman, A. (1988): "The collapse of the fixed exchange rate regime with sticky wages and imperfect substitutability between domestic and foreign bonds". European Economic Review, 32, 1817-1838.

Willman, A. (1992): "Studies in the theory of balance-of-payments crises". Bank of Finland Publications, Series B:46. 
